\title{
The Investigation of Reducing PAHs Emission from Coal Pyrolysis by Gaseous Catalytic Cracking
}

\author{
Yulong Wang, Ruifang Zhao, Chun Zhang, Guanlong Li, Jing Zhang, and Fan Li
}

State Key Laboratory Breeding Base of Coal Science and Technology Co-founded by Shanxi Province and the Ministry of Science and Technology, Taiyuan University of Technology, Taiyuan 030024, China

Correspondence should be addressed to Fan Li; lifan66@hotmail.com

Received 28 March 2014; Accepted 30 April 2014; Published 14 May 2014

Academic Editor: Arman Siahvashi

Copyright (C) 2014 Yulong Wang et al. This is an open access article distributed under the Creative Commons Attribution License, which permits unrestricted use, distribution, and reproduction in any medium, provided the original work is properly cited.

The catalytic cracking method of PAHs for the pyrolysis gaseous products is proposed to control their pollution to the environment. In this study, the Py-GC-MS is used to investigate in situ the catalytic effect of $\mathrm{CaO}$ and $\mathrm{Fe}_{2} \mathrm{O}_{3}$ on the 16 PAHs from Pingshuo coal pyrolysis under different catalytic temperatures and catalyst particle sizes. The results demonstrate that $\mathrm{Fe}_{2} \mathrm{O}_{3}$ is effective than that of $\mathrm{CaO}$ for catalytic cracking of $16 \mathrm{PAHs}$ and that their catalytic temperature corresponding to the maximum PAHs cracking rates is different. The PAHs cracking rate is up to $60.59 \%$ for $\mathrm{Fe}_{2} \mathrm{O}_{3}$ at $600^{\circ} \mathrm{C}$ and is $52.88 \%$ at $700^{\circ} \mathrm{C}$ for $\mathrm{CaO}$. The catalytic temperature and particle size of the catalysts have a significant effect on PAHs cracking rate and $\mathrm{CaO}$ will lose the capability of decreasing 16 PAHs when the temperature is higher than $900^{\circ} \mathrm{C}$. The possible cracking process of $16 \mathrm{PAHs}$ is deduced by elaborately analyzing the cracking effect of the two catalysts on 16 different species of PAHs.

\section{Introduction}

Polycyclic aromatic hydrocarbons (PAHs) are hazardous organic pollutants widely existing in the environment. Many of them have the carcinogenic, teratogenic, and mutagenic effects which mainly come from incomplete combustion of fossil fuels and hydrocarbons or from the pyrolysis in their reducing process [1]. Although the amount of PAHs in environment is trace, it has become a great menace to human health because it distributes widely in the air, soil, water, and vegetation through continuous generation, transformation, migration, and degradation and will enter the human body through the respiratory tract, skin, and digestive tract. Consequently, the sources of PAHs have received considerable attention from people.

The coal pyrolysis is the most important step of coal conversion process, and the thermal processing of coal is considered as the main source of PAHs in the environments [2]. The generation and emission control of PAHs in the coal transforming processing were focused on by many researchers. In recent years, many researchers have investigated the influence of metal oxide catalysts on PAHs yields during coal combustion and organic matter decomposition [3-7]. A prominent catalytic effect on cracking biomass oil by using olivine or dolomite was found [8-11]. Using the characteristic online coal pyrolysis and products catalytic cracking analysis technology, this paper probed into the cracking effects of $\mathrm{CaO}$ or $\mathrm{Fe}_{2} \mathrm{O}_{3}$ which were the main effective compositions of olivine or dolomite on the 16 PAHs of the coal pyrolysis products on the Environmental Protection Agency (EPA) Priority Pollutant List. The applicable catalysts and catalytic conditions reducing the PAHs emission during coal pyrolysis were selected. The results also provided a theoretical foundation for the industrial application.

\section{Materials and Methods}

\subsection{Materials}

2.1.1. Coal Sample. PS coal (from Pingshuo coal mine, China) that can generate more PAHs during coal pyrolysis was chosen as the sample in the study. The particle size was between 100 and 120 mesh. The proximate and ultimate analysis of PS coal was shown in Table 1. 
TABLE 1: Proximate and ultimate analysis of PS coal.

\begin{tabular}{lccccccc}
\hline \multicolumn{3}{l}{ Proximate analysis wt/\% } & \multicolumn{5}{c}{ Ultimate analysis wt/\%, daf } \\
\hline$M_{\mathrm{ad}}$ & $A_{d}$ & $V_{\mathrm{daf}}$ & $\mathrm{C}$ & $\mathrm{H}$ & $\mathrm{O}^{*}$ & $\mathrm{~N}$ & $\mathrm{~S}$ \\
2.2 & 18.3 & 37.2 & 80.4 & 5.2 & 11.9 & 1.4 & 1.1 \\
\hline
\end{tabular}

ad: air dried basis.

$d$ : dried basis.

daf: dry and ash-free basis.

${ }^{*}$ By difference.

2.1.2. Catalysts. Analytical pure calcium oxide $(\mathrm{CaO})$ and andiron oxide $\left(\mathrm{Fe}_{2} \mathrm{O}_{3}\right)$ were used as the catalysts and were crushed to 60-80 mesh, 100-120 mesh, 140-160, and 180200 mesh, respectively.

2.1.3. Chemicals and Reagents for the Experiment. The mixed standard sample of the 16 PAHs was supplied by Accustandard Inc. (concentration: $200 \mathrm{mg} / \mathrm{mL}$; solvent, a mixture of methanol, and dichloromethane, $\mathrm{v}: \mathrm{v}=1: 1$ ).

2.2. Experiment Procedure. Pyroprobe CDS 5250 pyrolyser coupled with FOCUS gas chromatograph and DSQII mass spectrometer (Thermo Fisher, USA) was used in this study. The connection and detective condition of GC-MS was presented in Dong et al. [12]. In each experiment, the catalyst was placed in a quartz filler tube which was firstly filled with a long quartz filler rod designed for use with the autosampler. Then, the catalyst was placed above the coal and they were separate by some quartz wool. It is functioned as a fixed bed, so that all the pyrolysis vapors will pass through the catalyst layer. The pyrolysis temperature was set differently, with a heating rate of $10^{\circ} \mathrm{C} / \mathrm{ms}$. The coal pyrolysis products were cracked by the catalyst on catalyst layer and the products were analyzed by the GC-MS for qualitative or quantitative analysis. Helium was used as the carrier with a flow rate of $1 \mathrm{~mL} / \mathrm{min}$.

2.3. Quantitative Analysis of PAHs. For the convenience of investigating the catalytic effects of metallic oxidant on PAHs with different ring number, the 16 PAHs were divided into LMW-PAHs (2-3 rings PAHs): naphthalene (2 rings), acenaphthylene (3 rings), acenaphthene (3 rings), fluorene ( 3 rings), phenanthrene (3 rings), anthracene (3 rings), MMWPAHs ( 4 rings PAHs): fluoranthene (4 rings), pyrene (4 rings), benzo[a]anthracene (4 rings), chrysene (4 rings), HMWPAHs (5-6 rings PAHs): benzo[b]auoranthene (5 rings), benzo[k]fluoranthene (5 rings), benzo[a]pyrene (5 rings), indeo[123-c,d]pyrene (6 rings), dibenz[a,h] anthracene (6 rings), and benzo[g,h,i]perylene (6 rings) [13].

The cracking rate of 16 PAHs was defined as

$$
X=\frac{C_{1}-C_{2}}{C_{1}} \times 100 \%
$$

where $C_{1}$ is the concentration of 16 PAHs in pyrolysis gas and $\mathrm{C}_{2}$ is the concentration of 16 PAHs after catalytic cracking.

The quantitative analysis of 16 PAHs was performed by the external standard method. The standard curve of 16

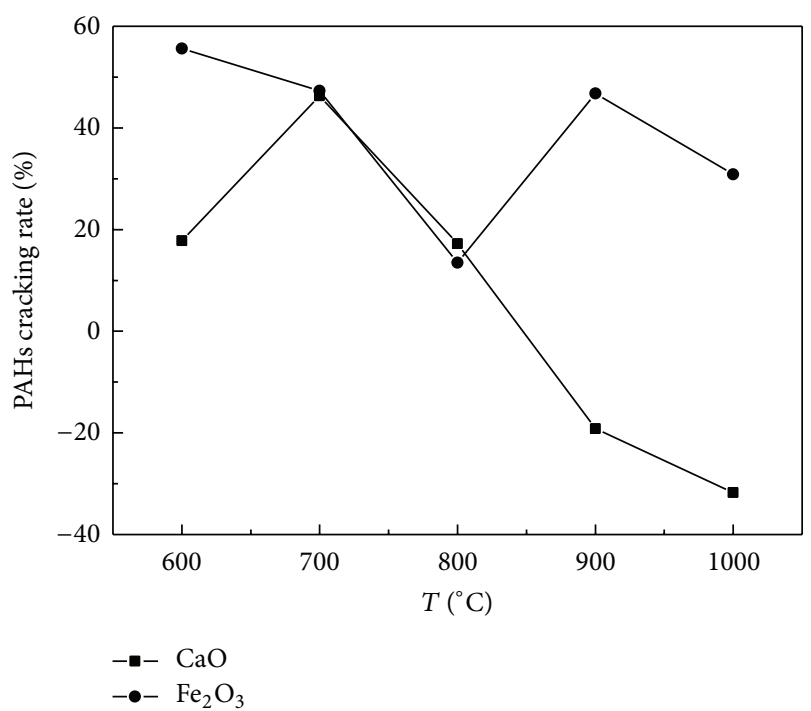

FIgURE 1: Relationship between the total PAHs cracking rate and temperature under effect of catalysts.

PAHs was generated by the GC-MS using five PAHs standard solutions with different PAHs concentrations $(0.2 \mu \mathrm{g} / \mathrm{mL}$, $0.4 \mu \mathrm{g} / \mathrm{mL}, 0.8 \mu \mathrm{g} / \mathrm{mL}, 1.0 \mu \mathrm{g} / \mathrm{mL}$, and $1.2 \mu \mathrm{g} / \mathrm{mL})$. The correlation coefficient $\left(r^{2}\right)$ of each standard curve was greater than or equal to 0.991 . In order to research the effect of metallic oxide on PAHs, the quantitative analysis of 16 PAHs was performed by mass spectrometer in SIM mode which had high selectivity and sensibility for the PAHs. Meanwhile, the qualitative analysis of pyrolysis production was performed by mass spectrometer in full scan mode to study the change of some important compounds in the pyrolysis process. All the experiments were replicated at least three times to make sure that the results were reproducible. Quality control of PAHs analysis was the same as the previous study [12].

\section{Results and Discussion}

3.1. The Effects of Temperature on Catalytic Cracking of PAHs. The influences of temperature were discussed on the emission of 16 PAHs cracked by $\mathrm{CaO}$ and $\mathrm{Fe}_{2} \mathrm{O}_{3}$ during coal pyrolysis, and the amount and the particle size of $\mathrm{CaO}$ and $\mathrm{Fe}_{2} \mathrm{O}_{3}$ were $0.4 \mathrm{mg}$ and 140-160 mesh, respectively. Figure 1 showed that $\mathrm{CaO}$ and $\mathrm{Fe}_{2} \mathrm{O}_{3}$ can reduce the total PAHs (represented the total amount of $16 \mathrm{PAHs}$ ). The maximum cracking rate for $\mathrm{Fe}_{2} \mathrm{O}_{3}$ is $55.64 \%$ at $600^{\circ} \mathrm{C}$ and it is better than that of $\mathrm{CaO}$ which is $44.29 \%$ at $700^{\circ} \mathrm{C}$.

It can be inferred that there were many active centers on the $\mathrm{CaO}$ surface. These active centers could deform $\pi$ electron cloud of the condensed aromatic compounds generated from the coal pyrolysis [14]. That is to say, the stability of PAHs was weakened and the activation energy of catalytic cracking PAHs was lowered. It illustrated that $\mathrm{CaO}$ was advantageous in cracking PAHs.

When the temperature is higher than $900^{\circ} \mathrm{C}$, total account of PAHs from catalytic cracking coal pyrolysis products was higher than that generated from the raw coal pyrolysis. As 


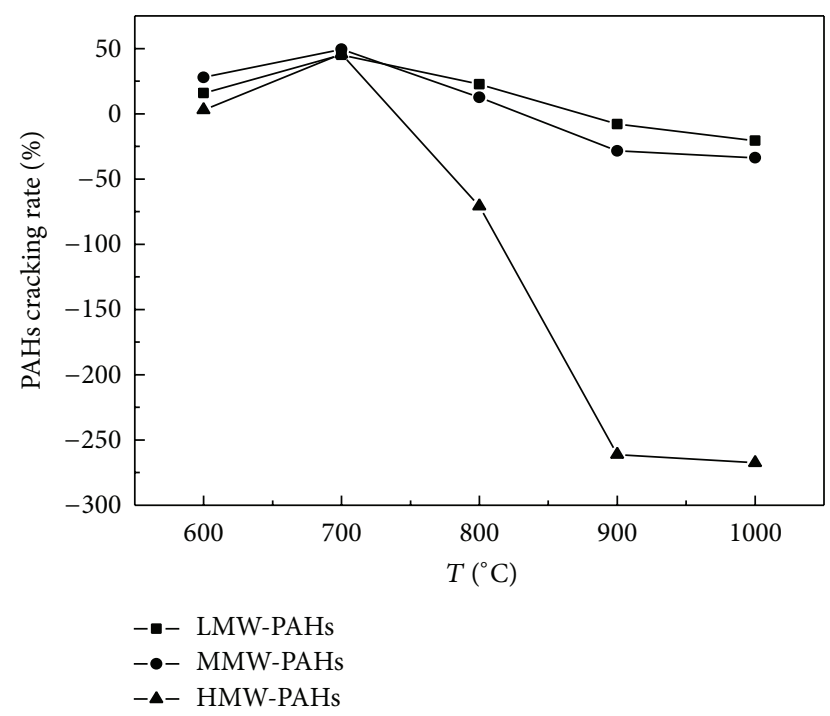

FIGURE 2: Relationship between the rings cracking rate distribution of PAHs and temperature under effect of $\mathrm{CaO}$.

is shown by Figures 1 and 2, the PAHs cracking rate increased with the increase of temperature, especially that of the HMW-PAHs. At a high temperature $\left(900-1000^{\circ} \mathrm{C}\right), \mathrm{CaO}$ played a major role in PAHs dehydrogenization which led to a polycondensation of PAHs [15], generating more PAHs from the catalytic coal pyrolysis products.

So the conclusion was that $\mathrm{CaO}$ had different catalytic roles at different temperatures for PAHs. At the high temperatures, $\mathrm{CaO}$ would lose the capability of decreasing 16 PAHs. At the low temperatures $\left(600-800^{\circ} \mathrm{C}\right), \mathrm{CaO}$ played a major role in catalytic cracking of $\mathrm{PAHs}$.

Compared with $\mathrm{CaO}, \mathrm{Fe}_{2} \mathrm{O}_{3}$ was observed to have the cracking effect on PAHs at different temperatures $\left(600^{\circ} \mathrm{C}\right.$, $700^{\circ} \mathrm{C}, 800^{\circ} \mathrm{C}, 900^{\circ} \mathrm{C}$, and $1000^{\circ} \mathrm{C}$ ), but the cracking rate for total PAHs did not reveal a principle tendency with the increase of the temperature. At $800^{\circ} \mathrm{C}$, the total PAHs cracking rate was the minimum for $\mathrm{Fe}_{2} \mathrm{O}_{3}$. Some possible reasons are that the coal pyrolysis process released $\mathrm{CO}$ and $\mathrm{H}_{2}$ reacting with $\mathrm{Fe}_{2} \mathrm{O}_{3}$ and the products $\mathrm{Fe}_{3} \mathrm{O}_{4}, \mathrm{FeO}$, and $\mathrm{Fe}$ or other materials were generated and had an effect on catalytic cracking of PAHs [16].

By comparing Figures 2 and 3, it can be found that the cracking capacity of $\mathrm{Fe}_{2} \mathrm{O}_{3}$ on LMW-PAHs and MMW-PAHs was better than that of $\mathrm{CaO}$ at a temperature in the range of $600^{\circ} \mathrm{C}-700^{\circ} \mathrm{C}$. $\mathrm{CaO}$ exposed a better cracking capacity on LMW-PAHs at $800^{\circ} \mathrm{C}$ than $\mathrm{Fe}_{2} \mathrm{O}_{3}$, and the corresponding cracking capacity on MMW-PAHs for the two catalysts was similar. When the temperature was higher than $900^{\circ} \mathrm{C}$, $\mathrm{Fe}_{2} \mathrm{O}_{3}$ exposed cracking effect on LMW-PAHs and MMWPAHs while $\mathrm{CaO}$ had the catalytic forming effect on all the PAHs. Besides, a more remarkable catalytic forming effect on $\mathrm{HMW}$-PAHs was found at $1000^{\circ} \mathrm{C}$ by $\mathrm{CaO}$.

3.2. Effects of Particle Size during Catalytic Cracking of PAHs. In order to reveal the influence of catalysts particle sizes on the catalytic cracking effect, different particle sizes (6080 mesh, 100-120 mesh, 140-160 mesh, and 180-200 mesh)

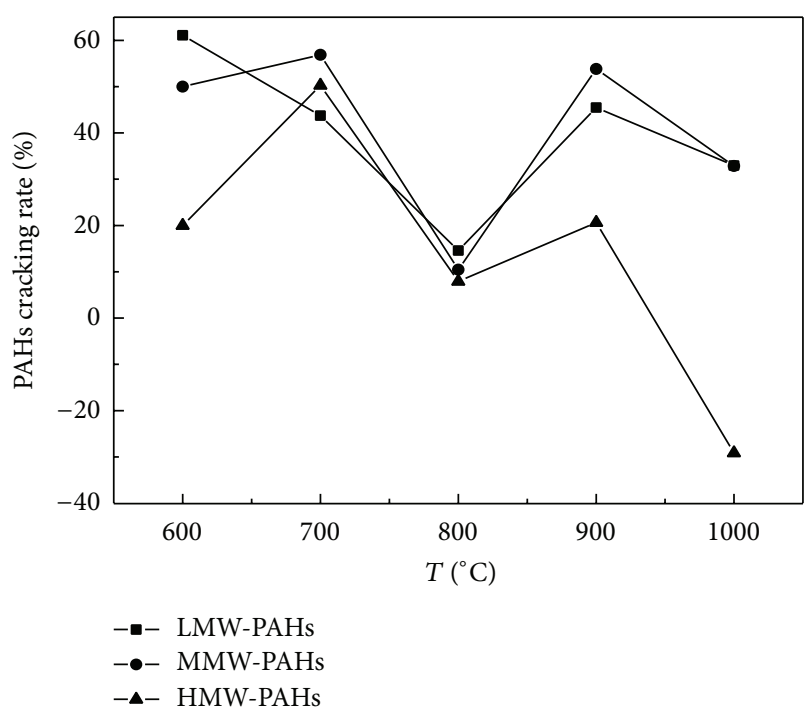

FIGURE 3: Relationship between the rings cracking rate distribution of PAHs and temperature under effect of $\mathrm{Fe}_{2} \mathrm{O}_{3}$.

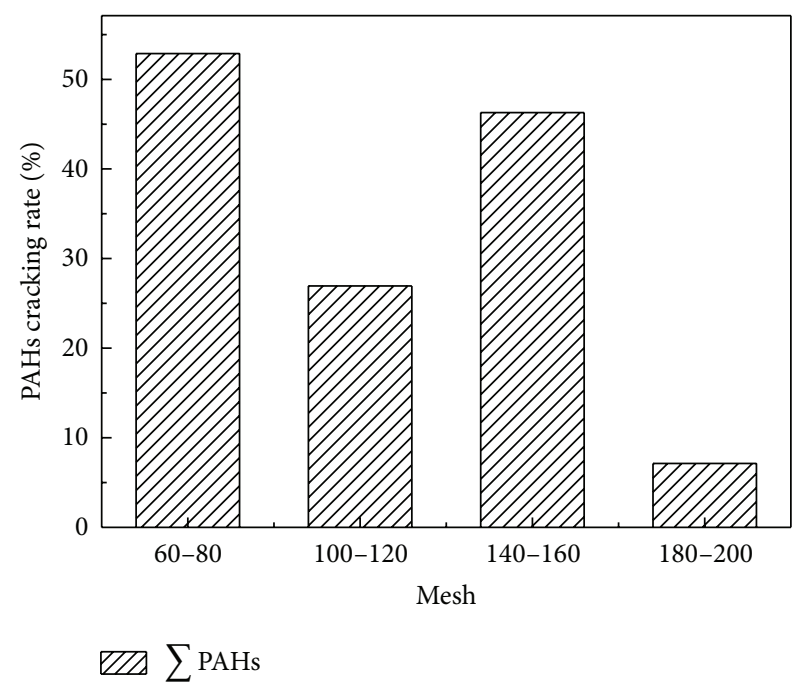

FIgURE 4: Relationship between the total PAHs cracking rate and particle size of $\mathrm{CaO}$.

were selected for a fixed amount of catalyst. Temperatures of $700^{\circ} \mathrm{C}$ and $600^{\circ} \mathrm{C}$ were chosen which were the highest cracking rate for $\mathrm{CaO}$ and $\mathrm{Fe}_{2} \mathrm{O}_{3}$, respectively. The amount of catalysts was set to $0.4 \mathrm{mg}$.

Figures 4 and 5 demonstrated that the total PAHs cracking rate decreased with the decrease of catalyst particle size. The maximum cracking rate of PAHs was $52.88 \%$ and $60.59 \%$, respectively, for $\mathrm{CaO}$ and $\mathrm{Fe}_{2} \mathrm{O}_{3}$ with 60-80 mesh. Figures 6 and 7 showed that the cracking rate of LMW-PAHs and MMW-PAHs declined with the increase of particle size through $\mathrm{CaO}$ or $\mathrm{Fe}_{2} \mathrm{O}_{3}$, while the HMW-PAHs cracking rate had a contrary tendency. The reason for these phenomena could be that the cracking activity of two catalysts increased with the increase of particle size. The organic macromolecular 


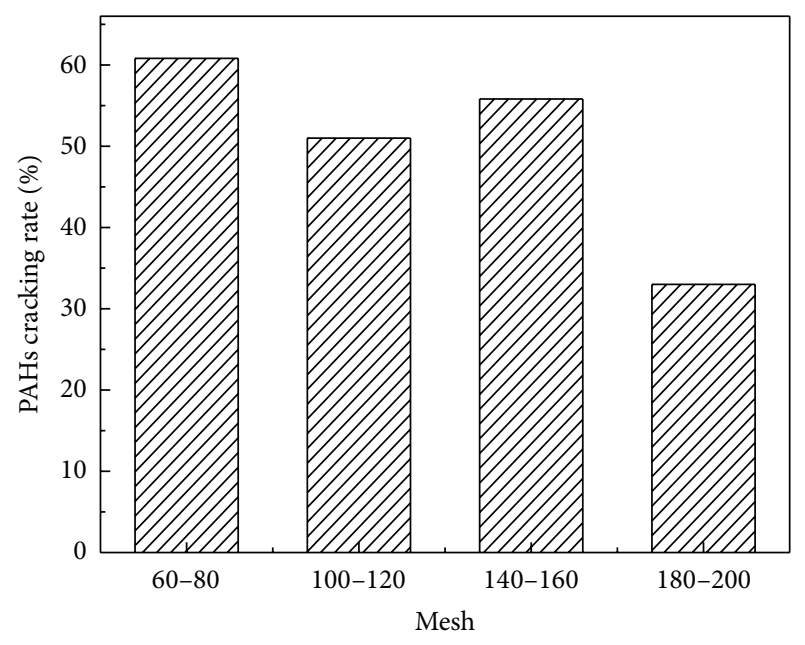

[थ] $\sum$ PAHs

Figure 5: Relationship between the total PAHs cracking rate and particle size of $\mathrm{Fe}_{2} \mathrm{O}_{3}$.

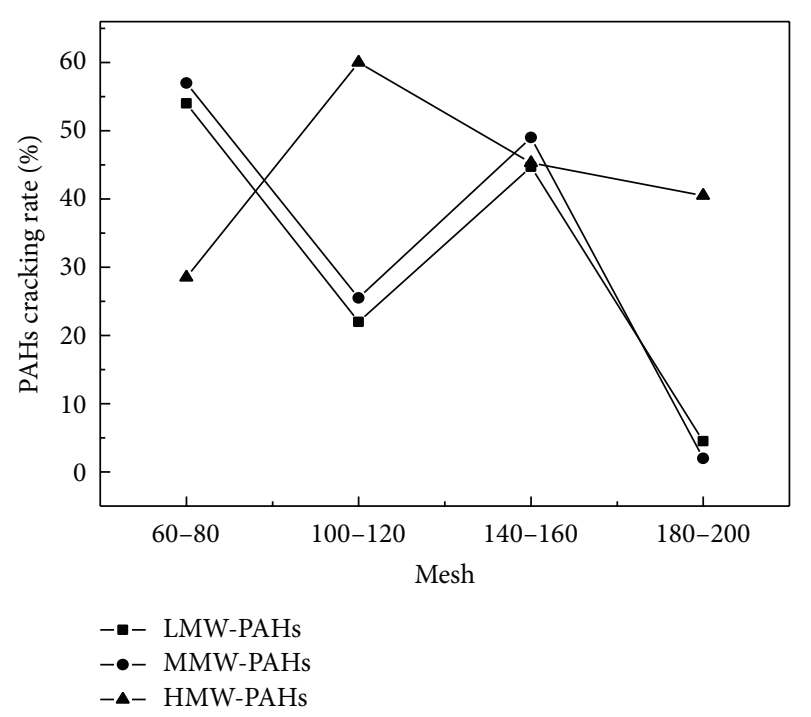

FIGURE 6: Relationship between the rings cracking rate distribution of PAHs and particle size of $\mathrm{CaO}$.

compounds cracked into the LMW-PAHs, MMW-PAHs, or gas products through catalysts, which cause an increase of LMW-PAHs and MMW-PAHs during coal pyrolysis. As a result, the cracking rate of LMW-PAHs and MMW-PAHs was decreased.

3.3. Catalytic Cracking Mechanism. To deeply understand the catalytic cracking effect on coal pyrolysis products and find out possible process formed or cracked the PAHs, the distribution of catalytic cracking products was analyzed in the GCMS on full scan mode. This experiment used $\mathrm{CaO}$ and $\mathrm{Fe}_{2} \mathrm{O}_{3}$ as catalysts with $0.4 \mathrm{mg}$ and $140-160$ mesh, respectively. $\mathrm{CaO}$ performed a catalytic cracking effect on $16 \mathrm{PAHs}$ at $700^{\circ} \mathrm{C}$ and

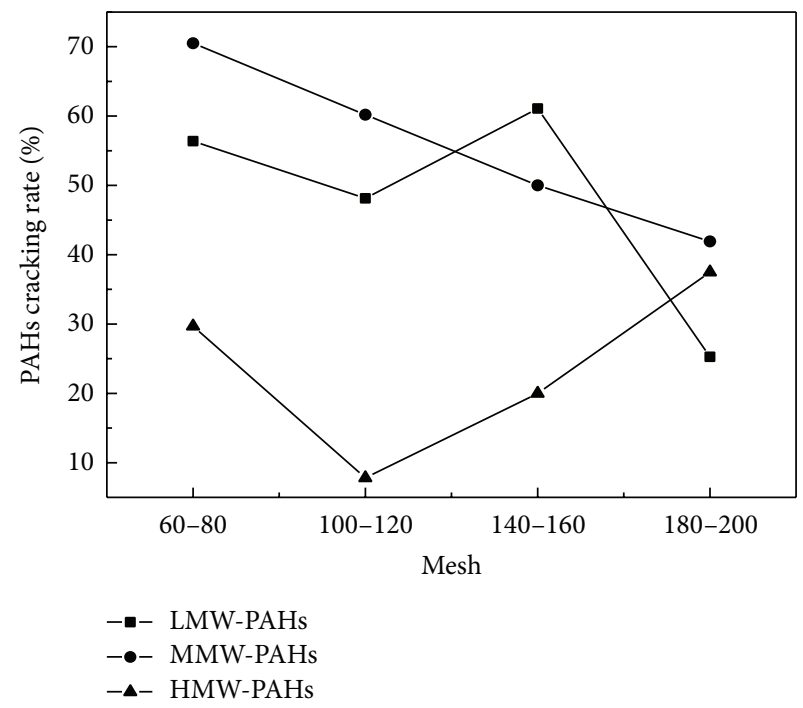

FIGURE 7: Relationship between the rings cracking rate distribution of PAHs and particle size of $\mathrm{Fe}_{2} \mathrm{O}_{3}$.<smiles>Cc1cccc(O)c1</smiles><smiles>Cc1ccc(C)c2c1CCC2</smiles><smiles>Cc1cc(C)cc(C(C)C)c1</smiles><smiles>Cc1ccc2ccccc2c1</smiles><smiles>CCc1ccc2ccccc2c1</smiles><smiles>Cc1cccc2c1Cc1ccccc1-2</smiles><smiles>Cc1ccc2ccc3ccc(C)cc3c2c1</smiles><smiles></smiles>

FIGURE 8: Portion products from coal pyrolysis.

a forming effect at $900^{\circ} \mathrm{C}$. But $\mathrm{Fe}_{2} \mathrm{O}_{3}$ only showed a catalytic cracking effect on 16 PAHs. So, $700^{\circ} \mathrm{C}$ was selected for the contrast.

The LMW-PAHs, MMW-PAHs and their isomers was shown in Figure 8, and they were catalyzed by $\mathrm{CaO}$ at $700^{\circ} \mathrm{C}$ as mentioned above. In addition, the PAHs and their derivatives were decreased synchronously. It was illustrated that $\mathrm{CaO}$ had an effect on breaking both the aromatic rings of PAHs, aromatic hydrocarbons with branches and aliphatic hydrocarbons. With the amount of naphthalene decreased by $\mathrm{CaO}$, the alkyl-substituent benzene also decreased. It was known that naphthalene is more favorable to transforming into the gas, small molecular alkanes and alkenes, alkylenesubstituent benzene, or their isomers.

In the case of methylnaphthalene, Figure 9 showed the probable path to forming and cracking of PAHs with $\mathrm{CaO}$. The compound on the left represents the aromatic ring with 


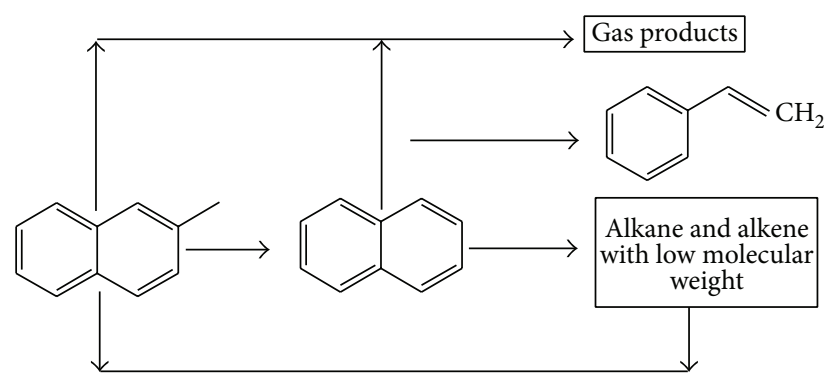

FIGURE 9: The schematic diagram of generating or cracking of naphthalene.

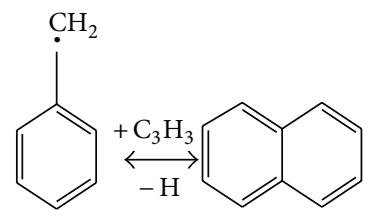

FIGURE 10: The polycondensation of methylbenzene.

branches, the naphthalene in the middle is aromatic ring, and the ethenylbenzene is the aromatic ring with alkenyl.

At $900^{\circ} \mathrm{C}, \mathrm{CaO}$ played a major role in PAHs dehydrogenation and catalyzed the coal pyrolysis products to polymerize. Taking methylbenzene as an example, when the temperature was higher, the methylbenzene should lose a hydrogen atom, then become the free radical; the free radical reacted with other lower weight molecules and formed naphthalene. On the contrary, the naphthalene and the methylbenzene increased. It was illuminated that the amount of naphthalene that came from free radical reaction was lower than that from other macromolecules cracked during the catalytic cracking process; the catalytic effect of $\mathrm{CaO}$ did not facilitate the naphthalene formation reaction shown in Figure 10. Also referring to Figure 2, $\mathrm{CaO}$ had a more significant forming effect on HMW-PAHs at $900^{\circ} \mathrm{C}$, but less on medium-lowring. It shows that $\mathrm{CaO}$ was possessed of selectivity on the polycondensation of PAHs.

Results of the experiment showed that the aromatic ring with aliphatic group could be transformed by $\mathrm{Fe}_{2} \mathrm{O}_{3}$, and some phenols such as phenol and cresol were formed after the catalytic cracking of $16 \mathrm{PAHs}$ by $\mathrm{Fe}_{2} \mathrm{O}_{3}$. The likely reason was that many reactive oxygen species $\left(\mathrm{O}_{2}{ }^{-}, \mathrm{O}_{2}{ }^{2-}, \mathrm{O}^{2-}\right)$ existed on the surface of metallic oxide [17]; these reactive oxygen species would crack the 16 priority controlled PAHs to some phenols.

\section{Conclusions}

$\mathrm{Fe}_{2} \mathrm{O}_{3}$ plays an obvious catalytic role than $\mathrm{CaO}$ in reducing PAHs emission during coal pyrolysis. Their catalytic temperature at which the splitting rate reaches its maximum is different, that is, $60.59 \%$ at $600^{\circ} \mathrm{C}$ for $\mathrm{Fe}_{2} \mathrm{O}_{3}$ and $52.88 \%$ at $700^{\circ} \mathrm{C}$ for $\mathrm{CaO}$, respectively.

$\mathrm{Fe}_{2} \mathrm{O}_{3}$ only shows a cracking effect on 16 PAHs and has better catalytic cracking effect for medium-low-ring PAHs than that of $\mathrm{CaO}$ in the temperature range of $600^{\circ} \mathrm{C}$ to $1000^{\circ} \mathrm{C}$. The cracking effect on PAHs of $\mathrm{CaO}$ is predominant at medium-low temperature. At higher temperature that effect is converted to promote the forming of $16 \mathrm{PAHs}$, which may be caused by more macromolecular PAHs split.

The cracking rate of 16 PAHs increases with the increase of the particle size of $\mathrm{CaO}$ and $\mathrm{Fe}_{2} \mathrm{O}_{3}$. This increase in the cracking rates mainly contributes to the medium-low-ring PAHs and the cracking rate of higher-ring PAHs tends to decrease.

The possible cracking process of PAHs from coal pyrolysis products is proposed by analyzing elaborately the cracking effect of the two catalysts on the 16 different PAHs species and comparing the composition difference of the pyrolysis products before and after the catalytic cracking. Some phenols may form after the catalytic cracking of $16 \mathrm{PAHs}$ by $\mathrm{Fe}_{2} \mathrm{O}_{3}$.

\section{Conflict of Interests}

The authors declare that there is no conflict of interests regarding the publication of this paper.

\section{Acknowledgments}

This work was supported by the National Natural Science Foundation under Grant 21376160 and International Science \& Technology Cooperation Program of China (2013DFG61490).

\section{References}

[1] T. Furuhata, Y. Kobayashi, K. Hayashida, and M. Arai, "Behavior of PAHs and PM in a diffusion flame of paraffin fuels," Fuel, vol. 91, no. 1, pp. 16-25, 2012.

[2] S. Xu, W. Liu, and S. Tao, "Emission of polycyclic aromatic hydrocarbons in China," Environmental Science and Technology, vol. 40, no. 3, pp. 702-708, 2006.

[3] M. J. Ahrens and C. V. Depree, "A source mixing model to apportion PAHs from coal tar and asphalt binders in street pavements and urban aquatic sediments," Chemosphere, vol. 81, no. 11, pp. 1526-1535, 2010.

[4] A. M. Mastral, M. Callen, and R. Murillo, "Assessment of PAH emissions as a function of coal combustion variables," Fuel, vol. 75, pp. 1553-1536, 1996.

[5] Y.-L. Wei and J.-H. Lee, "Manganese sulfate effect on PAH formation from polystyrene pyrolysis," Science of the Total Environment, vol. 228, no. 1, pp. 59-66, 1999.

[6] J. Müller, G. Dongmann, and C. G. B. Frischkorn, "The effect of aluminium on the formation of $\mathrm{PAH}$, Methyl-PAH and Chlorinated aromatic compounds during thermal decomposition of PVC," Journal of Aalyntical and Applied Pyrolysis, vol. 43, pp. 157-158, 1997.

[7] F.-Y. Chang, J.-C. Chen, and M.-Y. Wey, “The activity of Rh/ $\mathrm{Al}_{2} \mathrm{O}_{3}$ and $\mathrm{Rh}-\mathrm{Na} / \mathrm{Al}_{2} \mathrm{O}_{3}$ catalysts for PAHs removal in the waste incineration processes: effects of particulates, heavy metals, and acid gases," Fuel, vol. 88, no. 9, pp. 1563-1571, 2009.

[8] Y. F. Shen, P. T. Zhao, Q. F. Shao, D. C. Ma, F. Takahashi, and K. Yoshikawa, "In-situ catalytic conversion of tar using rice 
husk char-supported nickel-iron catalysts for biomass pyrolysis/gasification," Applied Catalysis B: Environmental, vol. 152, pp. 140-151, 2014.

[9] Q.-Z. Yu, C. Brage, T. Nordgreen, and K. Sjöström, "Effects of Chinese dolomites on tar cracking in gasification of birch," Fuel, vol. 88, no. 10, pp. 1922-1926, 2009.

[10] J. Corella, J. M. Toledo, and R. Padilla, "Olivine or dolomite as in-bed additive in biomass gasification with air in a fluidized bed: which is better?" Energy and Fuels, vol. 18, no. 3, pp. 713720, 2004.

[11] L. Devi, K. J. Ptasinski, and F. J. J. G. Janssen, "Pretreated olivine as tar removal catalyst for biomass gasifiers: investigation using naphthalene as model biomass tar," Fuel Processing Technology, vol. 86, no. 6, pp. 707-730, 2005.

[12] J. Dong, F. Li, and K. C. Xie, "Study on the source of polycyclic aromatic hydrocarbons (PAHs) during coal pyrolysis by PYGC-MS," Journal of Hazardous Materials, vol. 243, pp. 80-85, 2012.

[13] W.-J. Lee, M.-C. Liow, P.-J. Tsai, and L.-T. Hsieh, "Emission of polycyclic aromatic hydrocarbons from medical waste incinerators," Atmospheric Environment, vol. 36, no. 5, pp. 781-790, 2002.

[14] Y.-B. Jia, J.-J. Huang, and Y. Wang, "Effect of residence time on tar catalytic cracking behavior with calcium oxide," Journal of Combustion Science and Technology, vol. 10, no. 6, pp. 549-553, 2004.

[15] M. Widyawati, T. L. Church, N. H. Florin, and A. T. Harris, "Hydrogen synthesis from biomass pyrolysis with in situ carbon dioxide capture using calcium oxide," International Journal of Hydrogen Energy, vol. 36, no. 8, pp. 4800-4813, 2011.

[16] J. Li, C. H. Zhang, X. F. Cheng et al., "Effects of alkaline-earth metals on the structure, adsorption and catalytic behavior of iron-based Fischer-Tropsch synthesis catalysts," Applied Catalysis A: General, vol. 464, pp. 10-19, 2013.

[17] J. Zhang, Z. J. Wang, and Z. P. Zhu, “The inherent kinetic electrochemical reduction of oxygen into $\mathrm{H}_{2} \mathrm{O}$ on $\mathrm{FeN}_{4}$-carbon: a density functional theory study," Journal of Power Sources, vol. 255, pp. 65-69, 2014. 

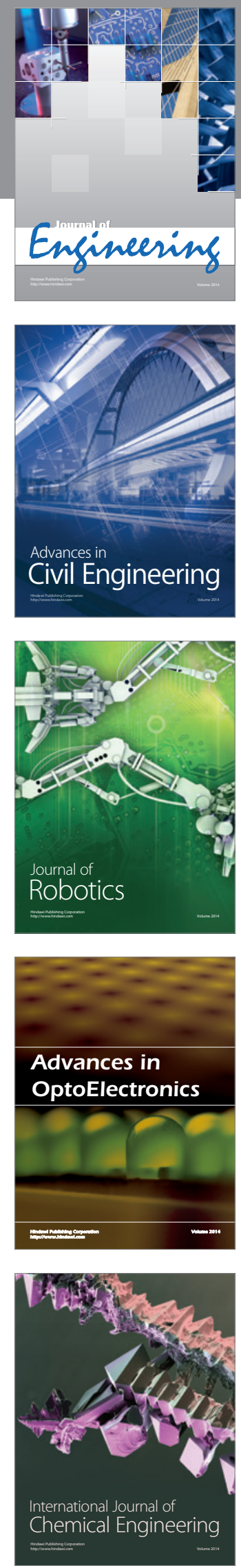

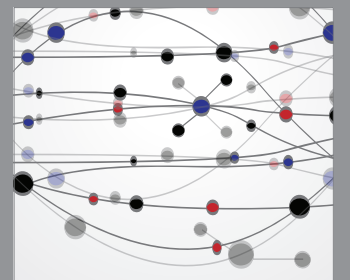

The Scientific World Journal
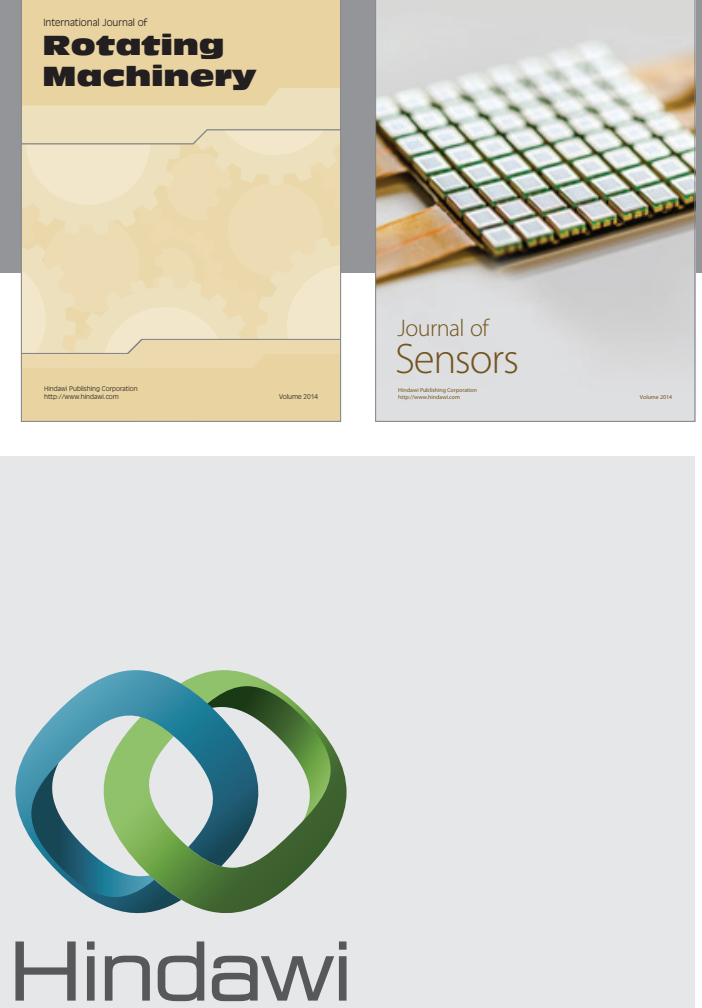

Submit your manuscripts at http://www.hindawi.com
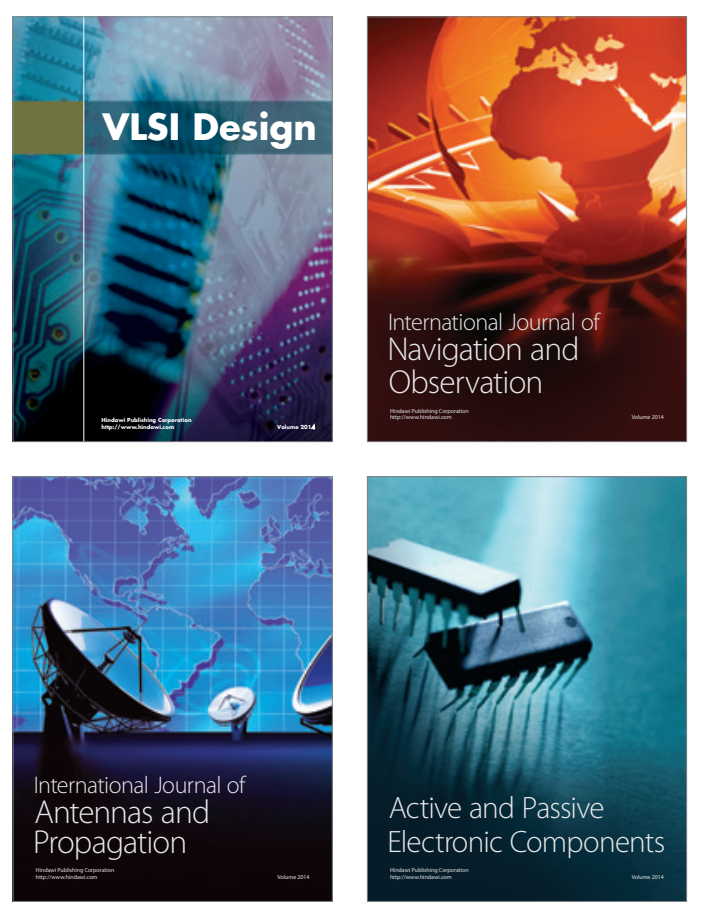
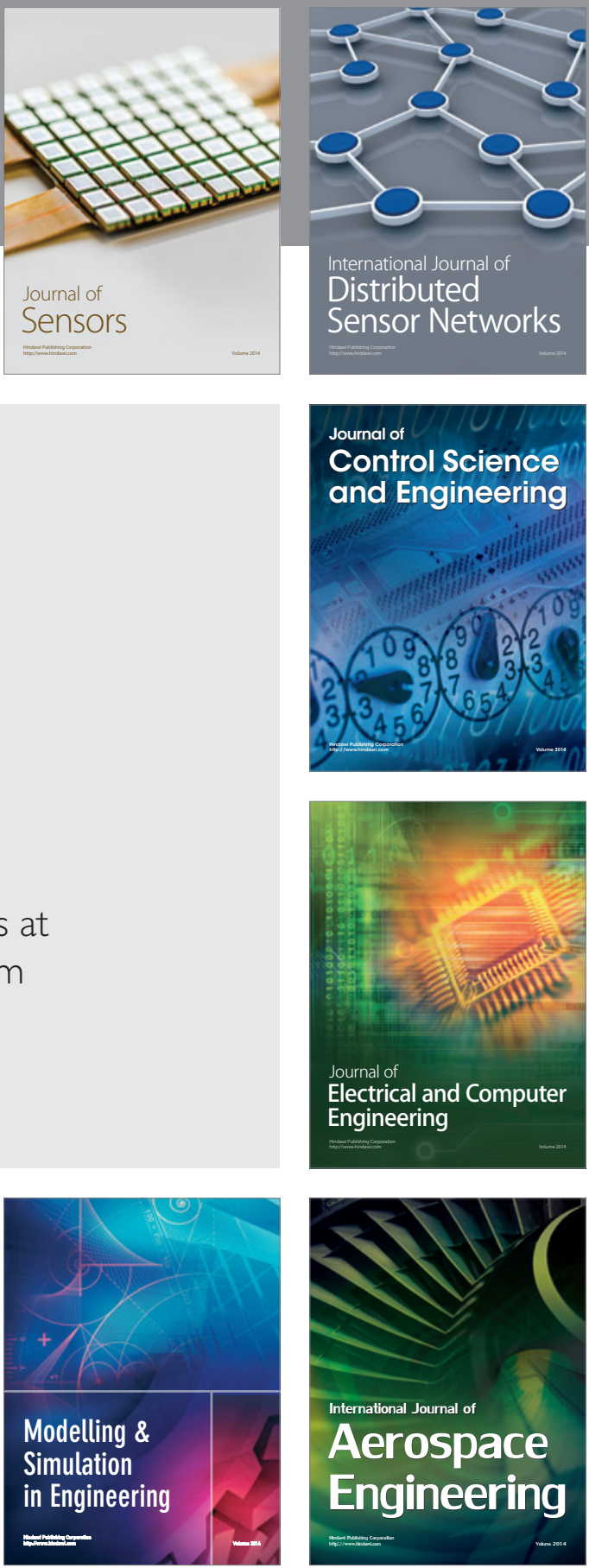

Journal of

Control Science

and Engineering
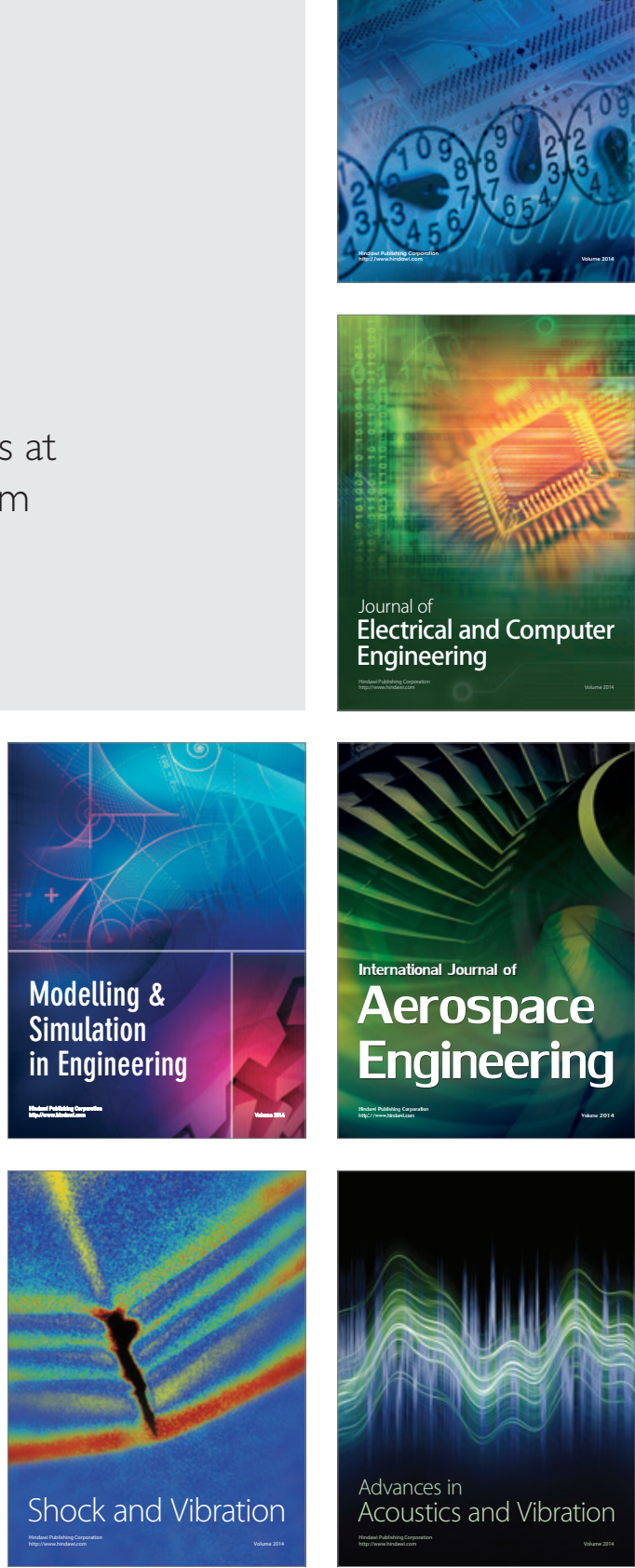